\title{
Centering Family Knowledge to Develop Children's Empowered Mathematics Identities
}

\author{
Ann M. Ishimaru \\ Filiberto Barajas-López \\ Megan Bang \\ College of Education, University of Washington \\ United States
}

\begin{abstract}
Researchers and educational leaders have long debated the appropriate roles and forms of family engagement in education. Although in recent years scholars have sought to understand how racially and linguistically diverse communities should participate in their children's education, the field has struggled to recognize and engage families' expertise and disrupt the dynamics of inequity that shape disengagement. In this conceptual paper, we highlight recent understandings regarding the development of disciplinary identities and cultural practices in learning to offer new approaches to the field of family engagement for conceptualizing the untapped potential of nondominant family knowledge and cultural practices in learning settings. By highlighting examples from mathematics learning that center families as legitimate sources of knowledge, we suggest avenues for engaging diverse family leadership in co-designing equitable learning environments that empower students' disciplinary identities and learning.
\end{abstract}

\section{Introduction}

Scholars and practitioners have long recognized that parents and families play a critical role in shaping and supporting student learning (Bryk, Sebring, Allensworth, Easton, \& Luppescu, 2010; Epstein, 2001; Henderson \& Mapp, 2002; Jeynes, 2012), yet there is little consensus in the field as to the roles and forms of family engagement that matter most for academic success, particularly in light of increasingly diverse students and families and persistent disparities in student outcomes. Despite the abundant rhetoric of parent-teacher partnerships to support student academic learning, a substantial body of research has identified the causes, barriers, and troubling implications of the asymmetric relationship between 
nondominant $^{\mathrm{i}}$ families and schools (Auerbach, 2007; Baquedano-López, Alexander, \& Hernandez, 2013; Carreón, Drake, \& Barton, 2005; Dyrness, 2009; Fine, 1993; Lareau \& Horvat, 1999; Olivos, 2006) As such, the field has begun to address deficit-oriented parent involvement approaches that seek to "fix" nondominant parents to adhere to normative (largely white, middle class) educator expectations and school-centric activities and goals.

A body of more critical approaches to community-based or collective family engagement suggests there are largely untapped sources of family expertise that support student academic success. Such expertise resides in nondominant families' social and cultural resources, lived experiences, collective agency, community leadership, and political power (Bolivar \& Chrispeels, 2011; Cooper, 2009; Hong, 2011; Lawson \& Alameda-Lawson, 2012; Lopez, 2001; Mediratta, Shah, \& McAlister, 2009; Pushor \& Murphy, 2004; Shirley, 1997; Warren, Hong, Rubin, \& Uy, 2009). Although such scholarship holds much promise in suggesting alternatives to deficit-based approaches and highlighting parent and family leadership in educational change efforts, much of this work has focused on broad engagement in schools outside of particular disciplinary contexts and the moment-to-moment interactions of teaching and learning (in and out of schools). Moreover, the field of family engagement continues to have limited knowledge regarding how to leverage this expertise and disrupt the dynamics of inequity that shape nondominant parent disengagement and disparities in student outcomes or school push-out.

Scholars from education fields outside of family engagement have also identified important expertise in nondominant families' cultural and linguistic repertoires, household economic knowledge, childrearing, everyday practices, and deeply-embedded epistemologies (for example, see Bang, 2015; Bang, Medin, Washinawatok, \& Chapman, 2010; Gutiérrez, 2008; Heath, 1983; Lareau, 2011; Lee, 2001; Moll, Amanti, Neff, \& Gonzalez, 1992; Nasir, Hand, \& Taylor, 2008). Thus, converging literatures and our collective work suggest that families play a key role in developing the identities that shape student engagement and learning.

However, the literature is more limited regarding the potential role of families relative to specific disciplines, such as mathematics and science, and how schools might collaborate equitably with families to build students' empowering and inclusive disciplinary identities. Scholars of culture and learning are increasingly considering disparities in youth engagement and learning around the intersections of disciplinary identities with racial, cultural, and gender identities. That is, students from underrepresented racial, ethnic, or immigrant communities often perceive themselves as faced with a false choice between their cultural/ethnic identities and particular academic or disciplinary identities (Nasir, 2012; Nasir \& Saxe, 2003). While there is a growing body of research focused on issues of identity development and, more specifically, on disciplinary and academic identity development (e.g., Bell et al, 2013), there has been limited focus on how families might collaborate with educators to build more empowered and holistic disciplinary identities across students' home, school, and community learning contexts. For example, professional educators are often presumed to be the sole experts and negotiators of disciplinary knowledge in schools, but the mostly white, middle class teaching force often feels ill-prepared to address issues of race, culture, class, sexual orientation, and other identities (Pollock, 2009). Educators alone are unlikely to have the knowledge or capacity to help students build holistic disciplinary and racial/cultural identities. Thus, based on converging lines of research undertaken by the authors, we argue that nondominant families can play a critical role in the development of children's empowered disciplinary identities, not only in the home but also in schools and communities. 
Addressing the gaps in our knowledge about families and learning has become particularly urgent in light of the persistent inequalities in opportunities to learn for students from nondominant communities, especially in mathematics and scientific disciplines where the disparities are particularly stark. In this paper, we draw on recent understandings from outside the field of family engagement to propose new avenues and possibilities for engaging nondominant parent and family expertise and leadership in teaching and learning in mathematics, specifically, and disciplinary learning more broadly. We first describe the conceptual foundations of our argument to highlight a central focus on family engagement in relation to two bodies of scholarship that offer key theoretical and empirical insights for recentering family knowledge in teaching and learning: the development of student disciplinary identities in mathematics and cultural practices in learning. We then provide a vignette as a suggestive example of how family knowledge and disciplinary understandings of mathematics might be reconceptualized and centered in learning interactions between students, teachers, and parents. Using this example, we make explicit the ways that racially and linguistically diverse families offer practical and theoretical insights to researchers and practitioners about their potential role and participation in their children's learning. We also discuss the limitations or challenges to enacting such work. Ultimately, we argue for the need to better understand how educators might equitably collaborate with nondominant families and communities to draw on the disciplinary expertise embedded in families. Such a fundamental shift in how we approach "family engagement" offers fertile ground for research and practice to create more equitable learning environments, opportunities, and outcomes for students across home, community, and school contexts.

\section{Conceptual Foundations}

We begin the discussion of the conceptual foundations of our argument by reviewing the extant literature from the family engagement field regarding mathematics learning, then highlighting the need for theoretical frameworks that attend to issues of power, cultural practices, and sociocultural contexts to guide future exploration in this domain, particularly in relation to students and families from historically marginalized communities. Whereas there has been important work in recognizing and cultivating nondominant family leadership in educational change efforts, the family engagement field has yet to delve deeply into specific disciplinary contexts, such as mathematics. We thus look to mathematics educators and others who have begun to examine how mathematics' disciplinary conceptions, student identity development, and student engagement and learning intersect and suggest critical roles for families. Finally, the literature on cultural practices in learning helps to tie these all together by illuminating how familial and community disciplinary knowledge embedded in cultural practices might be engaged through co-design efforts that leverage family decision-making to build equitable learning environments for students (e.g. Bang et al. 2010; Bang, 2015).

Family engagement in mathematics learning. Decades of research have firmly established the link between parent/family engagement and a broad range of student academic, social, and behavioral outcomes, including higher mathematics and science achievement (Sheldon \& Epstein, 2005; Van Voorhis, 2003). Yet, conventional efforts to enlist parent/family support, particularly in mathematics, often unintentionally exacerbate existing inequities and frame parents (regardless of background) as lacking mathematics understanding and capacity. 
Dramatic changes in mathematics education over the past two decades especially demonstrate the challenges for parental agency in supporting their children's mathematics learning (Remillard \& Jackson, 2006). The exclusion of parents from the discourse and implementation of reformoriented mathematics tended to reinforce teacher perceptions of parents, particularly from nondominant communities, as barriers or hindrances to student learning (Peressini, 1996).

More recently, a number of districts across the country have begun offering classes or "parent universities" to educate parents about the new Common Core mathematics standards so they will be better equipped to support their children with homework. Although well-intended and typically offered in response to parent requests, these parent education initiatives often mirror a deficit-based approach to parents and families that assumes they are lacking in knowledge and in need of "remediation" (Valencia \& Black, 2002). Although parents and families do struggle to reconcile the mathematics they learned in school with the mathematics their children are learning, without a more nuanced and reciprocal effort to leverage parent and family knowledge and practices, such approaches can fundamentally undermine parental/familial agency, disconnect learning that occurs in schools, families, and communities, and overlook cultural practices related to mathematics as a source of disciplinary expertise (e.g., Goldman \& Booker, 2009).

We argue for the need to build on the concept of families' "funds of knowledge" - or individual and household knowledge and skills related to the social, political, cultural, and labor histories of families - and the work that has been done to use that knowledge in school settings to improve instruction and increase opportunities to learn (Moll et al., 1992). Further research and practice might help us understand how to tap not only these funds of knowledge, but also families' lived experiences, cultural practices, disciplinary knowledge, and ways of knowing, through more reciprocal interactions that build sustained collaborative capacity. Whereas Moll and colleagues trained and supported teachers in becoming ethnographic researchers in their students' homes and then applying their findings to inform their instruction, we argue that parents and families can engage as equitable partners in the design, development, and teaching and learning of mathematics alongside educators. We argue for the transformative potential of positioning parents and families not only as sources of data and knowledge but also as fellow experts in the teaching and learning of their children. Booker \& Goldman (in press) argue that this is a necessary shift in repairing the systematic divide in mathematical learning between teachers and nondominant families. Further, they suggest that a critical requirement of repairing systems so that nondominant children thrive is restoring families' epistemic authority in mathematics learning by recognizing the ways in which mathematics is part of their everyday routines. We agree and suggest that restoring families' epistemic authority in mathematics also requires making visible the kinds of mathematics that are routine parts of families' cultural practices as well.

Although many school-based parent involvement efforts have limited success in meaningfully engaging nondominant parents (Fine, 1993; Schutz, 2006), an emerging body of work on community-based models of engagement identifies more relational, collective, and reciprocal approaches as promising strategies for strengthening parent and family leadership in systemic change and improving youth outcomes (Bang, Faber, Gurneau, Marin, \& Soto, 2015; Bang et al., 2010; Hong, 2011; Ishimaru, 2014; Oakes, Rogers, \& Lipton, 2006; Warren et al., 2009). For instance, work by Ishimaru and colleagues (in process) engaged nondominant parents, along with teachers, principals, and district leaders in co-designing a new parent education curriculum, which identified evolving design principles of equitable family-school 
collaboration. Within this effort, the development of students' positive racial and cultural identities emerged as a high priority for nondominant parents and an area of significant learning and growth for educators. The study also suggested possibilities for fundamentally shifting understandings and relationships between parents, teachers, and educational leaders in ways that could mitigate inequality in their students' schooling.

In tandem with these emerging efforts, the field of family engagement in the U.S. has increasingly recognized the need for "dual capacity": the knowledge, skills, and capacities of both parents and teachers to partner effectively to support student learning (Mapp \& Kuttner, 2013). Although a number of scholars have recognized the importance of examining family engagement in the context of "subject-specific practices" (Sheldon, Epstein, \& Galindo, 2010), the majority of the work in this area focuses on giving information to parents about student performance through traditional venues (e.g., parent-teacher conferences or open houses) or involving parents in homework focused on school-based learning activities that rarely address students' sociocultural contexts. The family engagement field has yet to deeply examine the disciplinary expertise of nondominant families and the potential for leveraging such understandings through family leadership in improving teaching and learning across contexts.

One potential reason for the scarcity of such research in family engagement is that the theoretical frameworks and methods employed in mainstream family engagement scholarship provide limited approaches for understanding familial disciplinary knowledge and the sociocultural contexts of learning. We next propose concepts from mathematics disciplinary identities and cultural practices in learning as critical guides for conceptualizing, examining, and building new theory and practices for engaging families in mathematics teaching and learning.

The development of disciplinary identities in mathematics. Students' development shapes engagement, motivation, learning, and outcomes in mathematics disciplines, and families play a key role in their children's academic socialization processes (Frome \& Eccles, 1998). Historically, mathematics has held a high social value that has positioned the discipline as an essential and important component of school (Apple, 1992; Martin, 2006; Powell, 2002). In schools, mathematics has been formalized to be about acquiring particular kinds of mathematical knowledge (e.g., concepts and facts). This is evident in the types of mathematics that are taught and expected from students when they transition through the K-12 system (e.g., from a hands-on use of concrete objects to make sense of situations that may require counting to using abstract reasoning to mathematically understand situations and scenarios in the middle grades).

With the recent adoption of Common Core State Standards and the Mathematical Practices (MP) associated with them in several states, the standards now reflect a commitment to a particular kind of content (e.g., what should be taught) and pedagogical stances about how students should learn the mathematics. For example, under MP \#4 (modeling with mathematics), students are now encouraged to create and solve real-world problems by moving between realworld scenarios and mathematical representations. While the idea of solving real-world problems is not new, the idea of connecting mathematical representations to explain real-world scenarios is laid out as a practice that mathematicians partake in. Yet, the standards provide no clarity about the types of real-world problems that make sense for students to engage with, given the racial and linguistic diversity across U.S. schools.

Furthermore, conventional school-based narratives of disciplinary practice tend to cultivate acultural and ahistorical disciplinary identities (Brown, 2004; Civil \& Quintos, 2009; Holland, Lachicotte, Skinner, \& Cain, 1998; Kane, 2012; Nasir \& Saxe, 2003) that marginalize 
students' racial and cultural identities. We know the development of racial and cultural identities is consequential for student learning and outcomes, but we have limited understanding about these issues specifically relative to mathematics and nondominant families (for notable exceptions see Nasir, 2002, 2000; Cvencek et al., 2014; Martin, 2009). For example, there is limited research of culturally responsive Latino/a parent engagement in school-based mathematics education (Civil \& Quintos, 2009). The few studies with Latino/a families that do exist have focused on two general areas of study: (a) parents' perceptions of mathematics teaching and learning in the receiving country, and (b) issues related to language instruction (Civil \& Planas, 2010).

However a growing body of work has significantly expanded our knowledge of the embedded mathematics in the everyday lives of students, families, and their communities. For example, Nasir's (2002) work explored how African American boys engaged in learning mathematics in out-of-school activities like basketball and dominoes. Participation in these activities showed how African American learners develop expertise, skills, practice and accountability within a collective learning process. Nasir and colleagues have found that the mathematical identities developed by African American boys outside of classroom contexts can be significantly more positive and agentic than in the context of more typical school-based instruction in mathematics, where African Americans learners have been historically marginalized. This work and other scholarship focused on the role of identity demonstrate that the everyday mathematics and cultural practices that youth and communities are engaged in are often invisible and under-utilized in classrooms (e.g., Aguirre et al., 2013; Esmonde et al., 2011; Martin, 2000; Nasir et al., 2008; Pea \& Martin, 2010).

Amongst scholars of mathematics education, the idea that becoming a 'certain type' of person or having an identity with respect to the practices of a community (Anderson, 2007; Martin, 2000, 2009) has gained greater traction. According to Sfard \& Prusak, (2005) identity refers the way an individuals see themselves and how others define these individuals relative to their life experiences and aspirations. In mathematics education, Martin (2009) defines mathematics identity as "the dispositions and deeply held beliefs that individuals develop about their ability to participate and perform effectively in mathematics contexts and to use mathematics to change conditions of their lives." An important takeaway from this perspective is that relationships and experiences with peers, teachers, and family/community contexts shape how students perceive their identities and engage with the discipline.

In his study with Mexican immigrant English learners, Barajas-López (2014) found that students' experiences with mathematics, across their elementary and secondary schooling, hinged on whether teachers presented these students with opportunities to form a positive identification with mathematics. A positive identification with mathematics and with the teacher, however, did not always produce lasting 'success' because these students often experienced restrictions and/or limitations associated with the English Learning (EL) context present in their schools. These restrictions included limited access to rigorous mathematics and curricula, teachers acting as key socializing agents in granting and/or withholding student participation, competency and connectedness to mathematics learning, and experiences of cultural bias and/or deficit thinking. Similarly, Martin (2006) highlights how African Americans experienced mathematics learning as a racialized experience that limited African Americans from seeing themselves as doers of mathematics, thereby limiting their life opportunities.

Thus, the literature on mathematics disciplinary identities point to the central notion that learning is not a simple cognitive process that unfolds inside individual children's heads. In 
addition, the literature points to the importance that adults (both teachers and parents) play in socializing youth to see themselves as doers and constructors of mathematics. Moreover, recent theories that conceptualize learning - and thus, identities - as complex, dynamic cultural processes can provide insights into how diverse families figure into the development of children's mathematics identities.

Cultural Practices in Learning. Research suggests the need to tightly interconnect learning that occurs across settings (homes, community settings, and schools) and that "learning is facilitated when the cultural, socio-economic, and historical contexts of learners are recognized, respected, and responded to" (Banks et al., 2007, p. 25). These practices have begun to be considered as important contexts for children in the development of their disciplinary identities. Although the culturally-based practices of nondominant communities are varied and can be productively engaged for learning, the repertoires of practice that nondominant children develop in their out-of-school lives are often narrated through deficit discourses.

We draw from a final body of literature to address the concept of culture, and the ways in which race is a product of culture, as the routine practices in which individuals and communities engage. This conception contrasts with "box models" of culture defined by categorical membership and tendencies to essentialize behaviors and beliefs of individuals assigned to such categories (Gutiérrez \& Rogoff, 2003; Lee, 2003; Nasir, Roseberry, Warren, \& Lee, 2006). As noted in Bell, et al. (2009), viewing learning in this way allows us to recognize that while children in all communities explore and narrate their worlds, they do so in varied ways that are dynamically connected to the particular constellations of relationships, values, goals, and worldviews of their communities (see also Bang, Warren, Rosebery, \& Medin, 2012; Rogoff, 2003). Further, these constellations impact the knowledge organization, reasoning patterns, and identities that children develop (Bang, 2015). Indeed these cultural processes are the contexts in which children learn to make sense of themselves and are made sense of by others (Herrenkohl \& Mertl, 2010; Holland et al., 1998).

This conception of culture and learning is important to distinguish from earlier efforts to address the growing diversity of students and families using a "cultural styles" approach to learning (Gutiérrez \& Rogoff, 2003). In the context of mathematics, for example, a trait-based approach to addressing diversity might take the form of embedding references to "ethnic" foods or traditions in story problems. Though well-intended, such efforts to adapt the curriculum to become more "culturally relevant" emphasize simplistic representations of "culture" that essentialize groups and reduce individuals to a set of traits based on membership in a broad category. Yet, such efforts often overlooked the underlying normative assumptions, structures, practices, pedagogies and disciplinary conceptions embedded in the cultural aspects of the mathematics being represented.

In contrast, leading scholars drawing on cultural-historical approaches to learning argue for the need to recognize that individuals participate in a range of communities both inside and outside of schools (Gutiérrez \& Rogoff, 2003). An understanding of students' and families' participation in the varied practices of "dynamic cultural communities" can provide insights to create learning spaces that build on these skills and practices (Gutiérrez, 2008; Lee, 2003). For instance, many (but not all) immigrant families from Mexico and Central America come from rural communities with long-standing agricultural practices rooted in complex indigenous understandings of relationships in the natural world. Families' participation in these community practices-often mediated through cultural artifacts and tools-suggests promising insights for 
expanding disciplinary conceptions of mathematics beyond narrow, school-based mathematical procedures.

Within this broader frame for culture and learning, then, we argue that mathematical practices can function as boundary objects (Akkerman \& Bakker, 2011) that embody certain roles, expectations, and tasks for children, parents and teachers. Whereas the default approach to mathematical practices and to engaging families around them can reinforce deficit dynamics, we argue for the need to design and examine approaches that seek to transform the roles and interactions of families, students, and educators. Such a reconceptualization of mathematical practices might engage family and cultural disciplinary knowledge. Such efforts would design mathematical learning activities to translate common ideas between different communities (between home communities and schools), facilitate new understandings and collaborative practices between parents, children, and teachers, and move beyond individualistic childcentered learning to address family-centered learning. In this case, educators would allow for mathematical practices that bridge school and home activity systems in ways that are infused with the social, cultural, and intellectual funds of knowledge of the home and community. In this context, cultural artifacts and tools - for example, those related to the indigenous agricultural practices of Mexican/Central American communities - can also serve as key boundary objects in such transformed mathematical practices (We develop the idea of agricultural practices serving as boundary objects in a vignette that we share in the next section).

To connect this idea to the previous discussion of mathematics identity development, we must recognize that learning and identity formation are closely interrelated, creating a "figured world" (Holland et al, 1998), or socially and culturally constructed spaces in which people, material objects, discourses, and practices interact within and across activities in specific places. That is, new forms of mathematical practices (rooted in family or community-based knowledge) may create new identity opportunities for students - as well as families and teachers - by shifting the nature of the "accumulation of daily stories and positionings" (Tucker-Raymond, Varelas, Pappas, Korzh, \& Wentland, 2007, p. 561) with respect to mathematics. By repositioning and reconceptualizing home and family cultural practices as mathematical practices, then, we might create spaces that help students build mathematics identities that are inclusive of their racial and cultural identities. For instance, students might shift from seeing mathematics as a static body of knowledge that other people own and use to perceiving mathematics as practices in which students' own families and communities engage, participate, and shape.

Recent work in science education by Bang and colleagues (e.g. Bang et. al, 2015; Bang \& Medin, 2010, Bang \& Marin, 2014; Bang et al., 2012) has built critical new understandings of how these theories might be applied in the context of nondominant families and communities. Bangr and colleagues engaged Native American families and extended community members to develop science learning programs in informal learning spaces (community centers, after-school programs, and summer programs) that intentionally built from children's and families' cultural and epistemic ecologies. The development of these programs engaged families and community members as lead designers and decision makers, teachers or facilitators, and even engaged families and community members as the researchers in studying, presenting, and publishing about these endeavors (Bang \& Marin, 2014; Bang et al., 2010). Further, the infrastructure of these efforts intentionally recognized the powered relationships between universities and community-based organizations and made deliberate and strategic efforts to recognize and leverage each others' expertise. For example, the community-based organization had a direct relationship to the funding organization, rather than a sub-contract from the university. 
Central to these design experiments was the premise that Indigenous youth would be more engaged in science if they saw and experienced it as relevant, connected, and useful to their communities and their cultural practices. A significant outcome of these studies was the dramatic transformations of parent and community understandings of science, and their own cultural practices in relation to science. Bang's work found reliable increases in students' productive disciplinary identities and shifts in their views to include community as a context for learning and doing science and included people in the community (elders, parents, and ancestors) as sources of science (Bang \& Medin, 2010). These findings suggest that when communities are in leadership and decision-making roles to develop and implement learning that reflects culturally and community based practices, they begin to form authentic identities as doers of science, and their conceptions of science, whether community or school-based, transition into more productive forms of engaged knowledge construction (Bang et al., 2012). While these studies were specific to science learning, the theoretical implications and processes are directly related to the issues we are raising in relation to family engagement and mathematics.

Synthesizing family engagement, disciplinary identities, and cultural practices in mathematics learning. In summary, the building of disciplinary identities is increasingly understood as critical to successful learning (Bell et al., 2009; Kane, 2012; Martin, 2007). Nasir (2011), writes, "As we engage in learning settings, our identities are constructed through expectations, the availability of roles, social interactions with others, and norms" (p. 29). Calabrese Barton and Brickhouse (2006) argue that identities have trajectories and that being seen by others in a community as engaging in disciplinary practices is key to putting youth on an identity trajectory towards fuller participation in a disciplinary communities. Thus, spaces that draw on family and community mathematics disciplinary knowledge might enable students to "become" a range of possible selves and lead to increasingly deep engagement with others in those practices. As one comes to see oneself as part of a larger social network, one starts to take on related identities and participate even more deeply in those coordinated activities.

Taken as a whole, we argue that these two bodies of work-disciplinary identities and cultural practices in learning-offer powerful theoretical concepts for the development of "next practices" in family engagement (Hargreaves \& Fullan, 2012). That is, we suggest that the field needs theory and practices that move us beyond - and indeed, shift the fundamental deficit-based assumptions embedded in-our current well-intentioned "best practices" in engaging nondominant families. Specifically in the case of mathematics, these concepts enable us to theorize how we might engage diverse families' leadership, cultural practices, and expertise through the co-design of family-based mathematical learning environments that enable students to build more inclusive and empowered mathematics-linked identities, thereby expanding opportunities to learn for nondominant students.

We turn next to a vignette that helps make concrete the synthesis of theoretical concepts discussed here and provides an illustrative example of the new directions and approaches for research and practice we suggest are made possible by bringing these bodies of work together. We do not draw on this example as empirical data but as a way of suggesting how the conceptual foundations described above might unfold in a real-world context. In the following vignette, we describe how a group of community-based educators used the Aztec calendar as a boundary object to engage Mexican and Central American families and students in a dialogue that began to surface culturally-based mathematical knowledge. It is important to note that the Aztec dancers were invited to present at a school by a well-meaning group of Latino educators to "expose" 
Latino students to culture. Although the session was not designed to elicit disciplinary knowledge, the interactions that emerged from the dialogue suggest fertile ground for next research and practices in collaborating with nondominant families to reconceptualize and cocreate more equitable mathematics learning environments.

\section{The Aztec Calendar as an Opening to Family-based Mathematics Knowledge}

As guests of the school, our group of Aztec dancers was invited to present and discuss indigenous teachings with Mexican-descent and Central American students and families because a group of concerned teachers perceived that these students needed to 'hear' more about their culture. We planned to show traditional indigenous dance from central Mexico, but we also planned to engage students in the deeper meanings of the drum, the regalia, the rattles, and some common symbols and representations that students have come to understand as indigenous but of the far distant past. One particular representation that we focused on was the ollin tonanitiuhtlan (movement of the sun) or what is commonly known as the Aztec calendar.

Upon asking students about what they knew about the stone, many described it as a 'calendar,' a 'beautiful image,' and as a symbol of Mexico's past. While students were quick to affirm the aesthetics of the monolith, for many of the middle and high school students attending the session, the stone no longer played a prominent role in society. According to students, the knowledge inscribed on the stone, the history, mathematics, science, and stories associated with it had been lost. Students asserted their point by stating that the calendar had no present-day meaning other than being used in t-shirt prints, tattoos, and textbooks.

Upon describing some of the meanings of the symbols, like the cycle of Venus being represented as twins on the stone-one representing the morning star and the other the evening star-and describing the two inscribed 'calendars'-one to count the cycle of the moon and the other to count the cycle of the sun-and the agricultural cycles associated with the lunar cycle, students began to ask more probing questions: "Why haven't we been taught this in our school?" "Where can we learn more about this?" "I feel like I've been kept away from important knowledge".

These questions also prompted their parents to make important connections with the cultural knowledge they inherited/possessed and brought with them from their homelands to the United States. One parent described the cycle of corn being represented in similar fashion to what we were describing mathematically on the stone. She explained that the season for corn to germinate took place during a 14-21-day period depending on the moisture on the soil. She continued to describe the rainy season, which accounts for 60-90 days during the summer season in central Mexico. There was also discussion about the 'fiestas' (celebrations) that are celebrated to mark the beginning and end of a season. Other parents made connections to the smell of copal (aromatic tree resin) and how it reminded them of particular experiences from their youth where they interacted with their elders and learned important stories about their family histories. Another parent expressed gratitude to the Aztec dancers for providing a space where their children could see them as knowledgeable about the richness of their cultural heritage and the complex ideas behind traditional practices like agriculture. 


\section{Fertile Ground for "Next" Research and Practices in Family Engagement}

The session described above represents a stark departure from the typical interactions of parents and students at school. Parents expressed that, prior to this experience, their participation in academics was limited to encouraging their children to do their homework and to attending school meetings. Some parents indicated that their children expressed resentment toward them because they could not support them with their academics, more specifically school mathematics, particularly once students transitioned from elementary to middle school and beyond. One parent recalled a school-organized family math function that had left him with many questions about how he could support his child if his language, culture, and knowledge were not acknowledged or a part of the math learning. There was no opportunity to share his ideas, his apprehensions, or his wishes as parent.

Parents and families as knowers and doers of mathematics. In the vignette above, we describe a problematic space that reveals the assumptions embedded in interactions between students, parents, and teachers in school settings. Within this space, parents are not positioned as legitimate sources of knowledge, and students' cultural practices are seen as unrelated to disciplinary learning. The initial discussion of symbols and representations revealed students' initial beliefs that traditional/indigenous cultures have not contributed to the development of modern mathematics and that their own families were removed from such mathematical knowledge, practices, and cultures. While well intentioned, the teachers' efforts to bring 'outsiders' to 'teach' students about their culture illustrates the degree to which students' cultural and racial identities are exclusive of academic identities. In this situation, then, parents were not positioned as contributors either to students' cultural and racial identities, or to their mathematical and disciplinary identities.

Unfortunately, the same dynamic is mirrored in the broader research where the contributions and knowledge of 'common people' and/or native peoples, with little or no formal schooling, are minimized or altogether ignored. Previously, Saxe (2012) has studied the relationship between mathematics and culture in Papua New Guinea (see also Saxe \& Esmonde, 2004). While this work has made explicit the unique ways in which the Oksapmin represent a counting system based on a 27-body-part count, this form of mathematics is reduced or simplified to 'simple' mathematics by the broader field of researchers and practitioners in the field of mathematics and mathematics education. However, the system of complex practices, knowledge, and representations associated with these mathematics are often overlooked due to a lack of comprehension by those outside of the particular culture/community and by dominant conceptions of mathematics that are assumed to be universal.

Returning to the example of the parents in the opening vignette, a deeper look reveals complex mathematical practices that are closely linked with agricultural practices around corn. For indigenous peoples in Mexico, and in other parts of this continent, corn has played an important role in the development of cultural and mathematical practices that remain an integral part of daily agricultural life in rural communities. These practices are derived from complex astronomical counts represented in the 'Aztec calendar' and in counting devices belonging to other indigenous communities that have been preserved. For example, the astronomical 'counts' represented in the 'Aztec calendar' reflect a complex system based on astronomical observation of the moon. Consequently, the mathematical cycles derived from the 28-day lunar cycles became part of the cultural, linguistic, and general cosmology of indigenous peoples. The 
relationship between the planting and harvesting of corn and the lunar cycles figured prominently in the ways in which native people from Mesoamerica used mathematics to make sense of the physical world. A whole system of knowledge, cultural values, and language captured the essence of why a particular number base was used (e.g., base 20), the significance of particular numbers in many everyday counting activities, and how the counting system was an elaborate representation of humans' intimate relationship to the earth and to the universe. Thus, this example demonstrates how the mathematics disciplinary knowledge embedded in cultural practices can reflect complexity that is often not engaged in school mathematics curricula, suggesting ways to expand conceptions of "what counts" as legitimate as well as possibilities for integrating across disciplinary boundaries.

This example, and the possibilities suggested by it, raise a provocative question: How might we collaborate with families to identify and conceptualize their disciplinary knowledge and co-create learning environments that enable students to build racially and culturally-based, agentic disciplinary identities? Ultimately, we argue that the concepts elaborated in this paper can inform new research and practice that seeks to address this pressing question.

We outline below suggestive directions for expanding on the emergent dialogue described in the vignette. We might imagine a series of collaborative sessions designed to uncover and make explicit families' identities in relation to mathematics that then work toward transforming and expanding these ideas in relationship with other parents through the co-creation of family-based mathematics learning activities. Teachers might also engage in the process with families to expand teachers' understandings of mathematics with respect to students' cultural practices and redesign classroom instruction to reflect the realities and lives of families. Building on the example above and extending it to the context of gardening, we highlight the contrast between more conventional school-based efforts to apply mathematics in this context and an effort that works to center family disciplinary knowledge and cultural practices in a collaborative effort to co-construct a mathematics learning environment.

Potential contexts for familial mathematics knowledge and cultural practices. Conventional school-based efforts to apply mathematics to gardening often involve the design of a garden where students calculate the area and perimeter of a plot of land at a school or measure the lengths of plants and count the number of petals. From this perspective, a primary goal is to help students understand how one can apply the concepts of area and perimeter to the design of a garden and use basic counting to keep track of plant growth. This approach, while more novel than textbook-based learning, privileges school-based notions of mathematics but does not engage broader understandings of mathematics in the context of cultural and human relationships with land and the earth's relationship with the broader universe. Returning to the Common Core idea of Mathematical Practice \#4 (modeling with mathematics), one can see the limitations that are assumed in school-based mathematics. The threshold for real-world applications is largely dependent on the cultural assumptions of teachers and school systems and can inadvertently deny or exclude real family experiences and cultural practices from being a part of the learning of mathematics.

But what would happen if parents were provided opportunities to share their experiences with the land? What if parents shared some of their insights on the cycle of plants and the relationship with calendar counts and number systems? We posit, based on prior work, that their children and teachers would begin to see them as knowers and doers of mathematics, that parents' ideas and contributions to math learning might change the way their children developed 
as math learners, and that schools might begin to view and engage families through a fundamentally different lens. While the example we shared in the vignette applies to nondominant families with origins in Mexico and Central America, the practice of agriculture is one that is a part of many cultures around the world. In one Pacific Northwest community, for example, numerous families of various origins-Hmong, African American, Latino and Native American-share a farm throughout the year, with each group of families adhering to particular plant rotation cycles depending on the season. In a multilingual and multicultural classroom setting that took up the transformative approaches we suggest, nondominant families from multiple communities would be able to make explicit the mathematical practices embedded in plant cycles from their cultures and investigate why certain types of plants and foods have become the primary source of sustenance and survival in that culture.

New directions for engaging families in mathematics teaching and learning. In conclusion, the literature and our previous work collectively suggest that nondominant family decision-making, familial disciplinary knowledge and cultural practices, and students' developing racial/cultural identities can be key levers for reducing inequality and enabling youth to achieve their potential. Specifically, we have argued for the need to:

1. engage families as knowers, doers, decision-makers, and co-designers in the core work of disciplinary teaching and learning across contexts;

2. recognize and interrogate the complexity of family and community-based mathematics knowledge embedded in cultural practices to expand disciplinary conceptions;

3. deepen understandings of families and communities' roles in the development of students' academic, disciplinary, racial and cultural identities.

Building on these understandings, we suggest that powerful new avenues for research and practice open when we engage families in leadership roles and center their disciplinary knowledge and cultural practices to create learning spaces that foster students' abilities to develop holistic, empowered disciplinary identities.

Such transformative possibilities do, however, face major limitations and challenges that are important to acknowledge. As our own research attests, fostering equitable collaboration between families and schools is difficult and ongoing work, highly time and resource-intensive, and necessitates entirely different educator capacities for interacting with families and constructing teaching and learning. We know that shifts in instructional practice entail ongoing investments and supports, and the field continues to struggle with how to build systematic and sustainable change in schools and school systems.

Not only must these new ways of doing and being supplant long-standing deficit-based approaches to nondominant parents and families, such efforts must also contend with the realities of schools in an era of standards and accountability. The current educational policy context constructs families in simplistic ways, as barriers to student success, as market-based consumers choosing "brands" of reform, or as compliant teachers' aides at home (Baquedano-Lopez et al., 2013). Neoliberal reforms - in tandem with the deficit-based parent involvement paradigm that continues to hold sway in most schools and systems-are part of a powerful colonizing movement in U.S. education. The systematic marginalization of families in education reflects a broader historical dynamic of imposing Eurocentric values and epistemologies on nondominant students, families, and communities and implicitly blaming them for disparities in educational outcomes (Tuhiwai Smith, 1999). Although it is beyond the scope of this paper to elaborate on dominant epistemologies and mechanisms of power, we contextualize our call for a fundamental 
transformation in the dynamics of family-school relations as part of a broader decolonizing project. As Baquedano-Lopez and colleagues discuss (2013), a decolonial approach to education and parent involvement "seeks to redress imbalances and exclusionary actions toward students and parents from nondominant communities" (p. 169).

In spite of the seeming enormity of such a transformation, we also see key convergences beginning to emerge across fields that hold promise for addressing these barriers and opening the way for the kinds of research and practice suggested by the conceptualizations in this paper. Growing policy and philanthropic interest has emerged in relation to addressing issues of equity in education (for example, district racial equity policies, initiatives on males of color, efforts to address racially disproportionate disciplinary practices, and funders like W.T. Grant and W.K. Kellogg Foundations investing in work to address inequalities). Similarly, a proliferation of cross-sector collaboration efforts, such as the "collective impact" initiatives, are seeking to reach beyond the school walls to broker more holistic solutions to systemic inequities and, increasingly, attend to racial inequalities and the role of families (Henig et al., 2015). Likewise, the family engagement field has begun to take up the call for racial equity and the need to build the educator capacity to engage families in ways that will lead to educational equity (Hinojosa \& Lopez, 2015). New national educational leadership standards prioritize "equity and cultural responsiveness" as a key responsibility of formal leaders, in addition to family and community engagement (CCSSO, 2015). And emerging theoretical and disciplinary developments are also pointing the way to decolonizing approaches. For example, scholars of culture, learning and development in the learning sciences are drawing on indigenous epistemologies and methodologies to elaborate new approaches for constructing equitable learning spaces. Collectively, these emerging dynamics represent a key opportunity to build a more conducive context and set of policy, resource, and theoretical levers for re-centering families in the work of educating children.

Ultimately, we argue for the need to reorient the notion of family engagement toward more empowering and equitable forms of collaboration with families. These converging bodies of scholarship and practice suggest a way forward that moves beyond simply reframing deficits as assets, removing barriers to participation, or efforts to make family and student engagement more "culturally-relevant" without fundamentally shifting the underlying assumptions, structures, norms, or practices. Rather, we envision a transformation in the role of nondominant parents and families from constrained and passive supporters in school-centric activities and agendas towards expert collaborators and fellow leaders in expanding disciplinary conceptions and reshaping teaching and learning across multiple contexts. We offer the synergy of these different lenses and bodies of work as fertile ground for new conceptualizations and next research and practices in building the collaborative capacity of educators and families to improve student engagement, learning, and well-being in our increasingly diverse schools and communities. 


\section{References}

Aguirre, J. M., Turner, E. E., Bartell, T. G., Kalinec-Craig, C., Foote, M. Q., Roth McDuffie, A., \& Drake, C. (2013). Making connections in practice: Developing prospective teachers' capacities to connect children's mathematical thinking and community funds of knowledge in mathematics instruction. Journal of Teacher Education, 64(2), 178-192.

Akkerman, S. F., \& Bakker, A. (2011). Boundary crossing and boundary objects. Review of Educational Research, 81(2), 132-169. http://doi.org/10.3102/0034654311404435

Anderson, R. (2007). Being a mathematics learner: Four faces of identity. Mathematics Educator, 17(1), 1-8.

Apple, M. W. (1992). Do the standards go far enough? Power, policy, and practice in mathematics education. Journal for Research in Mathematics Education, 23(5), 412-431. http://doi.org/10.2307/749562

Auerbach, S. (2007). From moral supporters to struggling advocates: Reconceptualizing parent roles in education through the experience of working-class families of color. Urban Education, 42(3), 250-283. http//doi.org/10.1177/0042085907300433

Bang, M. (2015). Culture, learning, and development and the natural world: The influences of situative perspectives. Educational Psychologist, 50(3), 220-233.

Bang, M., \& Marin, A. (2015). Nature-culture constructs in science learning: Human/nonhuman agency and intentionality. Journal of Research in Science Teaching, 52(4), 530544.

Bang, M., \& Medin, D. (2010). Cultural processes in science education: Supporting the navigation of multiple epistemologies. Science Education, 94(6), 1008-1026.

Bang, M., Medin, D., Washinawatok, K., \& Chapman, S. (2010). Innovations in culturally based science education through partnerships and community. In New Science of Learning (pp. 569-592). Springer New York.

Bang, M., Warren, B., Rosebery, A. S., \& Medin, D. (2012). Desettling expectations in science education. Human Development, 55(5-6), 302-318.

Bang, M., Faber, L., Gurneau, J., Marin, A., \& Soto, C. (2015). Community-Based Design Research: Learning Across Generations and Strategic Transformations of Institutional Relations Toward Axiological Innovations. Mind, Culture, and Activity, 1-14.

Banks, J. A., et al. (2007). Learning in and out of school in diverse environments: life-long, lifewide, life-deep. Seattle, WA: LIFE Center, University of Washington, Stanford University, and SRI International: Center for Multicultural Education, University of Washington, Seattle. 
Baquedano-López, P., Alexander, R. A., \& Hernandez, S. J. (2013). Equity issues in parental and community involvement in schools what teacher educators need to know. Review of Research in Education, 37, 149-182.

Barajas-López, F. (2014). Mexican immigrant students' schooling experiences and the construction of disengagement in mathematics learning contexts. Journal of Latinos \& Education, 13(1), 14-32.

Bell, P., Lewenstein, B., Shouse, A., \& Feder, M. (Eds.). (2009). Learning science in informal environments: people, places, and pursuits. Washington, D.C.: The National Academies Press.

Bolivar, J. M., \& Chrispeels, J. H. (2011). Enhancing parent leadership through building social and intellectual capital. American Educational Research Journal, 48(1), 4-38. http:/doi.org/10.3102/0002831210366466

Brown, B. A. (2004). Discursive identity: Assimilation into the culture of science and its implications for minority students. Journal of Research in Science Teaching, 41(8), 810834. http://doi.org/10.1002/tea.20228

Bryk, A. S., Sebring, P. B., Allensworth, E., Easton, J. Q., \& Luppescu, S. (2010). Organizing Schools for Improvement: Lessons from Chicago. Chicago: University of Chicago Press.

Calabrese Barton, A., \& Brickhouse, N. (2006). Engaging girls in science. In C. Skelton, B. Francis, \& Mulyan (Eds.), The SAGE Handbook of Gender and Education. London, England: SAGE Publications Ltd. Retrieved from https://books-googlecom.offcampus.lib.washington.edu/books/about/The_SAGE_Handbook_of_Gender_and _Educatio.html?id=4tVtro6MfksC

Carreón, G. P., Drake, C., \& Barton, A. C. (2005). The importance of presence: Immigrant parents' school engagement experiences. American Educational Research Journal, 42(3), 465-498. http://doi.org/10.3102/0002831204200346

Council of Chief State School Officers (2015). National policy board approves final professional standards for educational leaders.

http://www.ccsso.org/News_and_Events/Press_Releases/National_Policy_Board_Approv es_Final_Professional_Standards_for_Educational_Leaders.html\#sthash.yDdJvBcI.dpuf

Civil, M., \& Planas, N. (2010). Latino/a immigrant parents voices in mathematics education. In E. L. Grigorenko \& R. Takanishi (Eds.), Immigration, diversity, and education. New York: Routledge.

Civil, M., \& Quintos, B. (2009). Latina mothers' perceptions about the teaching and learning of mathematics: Implications for parental participation. In B. Greer, S. Mukhopadhyay, S. Nelson-Barber, A. B. Powell, \& A. B. Powell (Eds.), Culturally responsive mathematics education (pp. 321-343). New York: Routledge. 
Cooper, C. W. (2009). Performing cultural work in demographically changing schools: Implications for expanding transformative leadership frameworks. Educational Administration Quarterly. Retrieved from http://eaq.sagepub.com/content/early/2009/10/07/0013161X09341639.short

Cvencek, D., Nasir, N. I. S., O'Connor, K., Wischnia, S., \& Meltzoff, A. N. (2014). The development of math-race stereotypes: "They say Chinese people are the best at math". Journal of Research on Adolescence, 25(4), 630-637.

Dyrness, A. (2009). Cultural exclusion and critique in the era of good intentions: Using participatory research to transform parent roles in urban school reform. Social Justice, 36(4), 36-53.

Epstein, J. L. (2001). School, family, and community partnerships: preparing educators, and improving schools. Boulder, Colo.: Westview Press.

Esmonde, I., Pilner Blair, K., Goldman, S., Martin, L., Jimenez, O., \& Pea, R. (2011). Math I Am: What we learn from stories that people tell about math in their lives. In B. Bevan, P. K. Bell, R. Stevens, \& Razfar, A. (Eds.). LOST learning: Learning about out-of-schooltime learning opportunities. New York: Springer.

Fine, M. (1993). [Ap]parent involvement: Reflections on parents, power, and urban public schools \& responses. The Teachers College Record, 94(4), 682-729.

Frome, P. M., \& Eccles, J. S. (1998). Parents' influence on children's achievement related perceptions. Journal of Personality and Social Psychology, 74, 435-452.

Geoffrey B. Saxe. (2012). Cultural development of mathematical ideas: Papua New Guinea studies. New York: Cambridge University Press.

Gutiérrez, K. D. (2008). Developing a sociocritical literacy in the third space. Reading Research Quarterly, 43(2), 148-164. http://doi.org/10.1598/RRQ.43.2.3

Gutiérrez, K. D., \& Rogoff, B. (2003). Cultural ways of learning: individual traits or repertoires of practice. Educational Researcher, 32(5), 19-25.

Hargreaves, A., \& Fullan, M. (2012). Professional capital: transforming teaching in every school. New York; London: Teachers College Press.

Heath, S. B. (1983). Ways with words: Language, life and work in communities and classrooms. Cambridge, UK: Cambridge University Press.

Henderson, A. T., \& Mapp, K. L. (2002). A new wave of evidence: The impact of school, family, and community connections on student achievement. National Center for Family \& Community Connections with Schools, Southwest Educational Development Lab. 
Henig, J. R., Riehl, C. J., Rebell, M. A., \& Wolff, J. R. (2015). Putting collective impact in context: A review of the literature on local cross-sector collaboration to improve education. New York, NY: Teachers College, Columbia University, Department of Education Policy and Social Analysis.

Herrenkohl, L. R., \& Mertl, V. (2010). How students come to be, know, and do: a case for a broad view of learning. New York: Cambridge University Press.

Hinojoso, A. \& Lopez, E.M. (2015). Putting an equity lens on family engagement in Oregon. Cambridge, MA: Harvard Family Research Project.

Holland, D., Lachicotte, W., Skinner, D., \& Cain, C. (1998). Identity and agency in cultural worlds. Cambridge, Mass: Harvard University Press.

Hong, S. (2011). Cord of three strands: A new approach to parent engagement in schools. Harvard Education Press.

Ishimaru, A.M. (2014). Rewriting the rules of engagement: Elaborating a model of districtcommunity collaboration. Harvard Educational Review, 84(2).

Jeynes, W. (2012). A meta-analysis of the efficacy of different types of parental involvement programs for urban students. Urban Education, 47(4), 706-742. http://doi.org/10.1177/0042085912445643

Kane, J. M. (2012). Multiple identities and the science self: How a young African American boy positions himself in multiple worlds. In Maria Varelas (Ed.), Identity construction and science education research: learning, teaching, and being in multiple contexts. Rotterdam: Sense Publishers.

Lareau, A. (2011). Unequal childhoods: class, race, and family life (2nd ed., with an update a decade later). Berkeley: University of California Press.

Lareau, A., \& Horvat, E. M. (1999). Moments of social inclusion and exclusion race, class, and cultural capital in family-school relationships. Sociology of Education, 72(1), 37-53. http://doi.org/10.2307/2673185

Lawson, M. A., \& Alameda-Lawson, T. (2012). A case study of school-linked, collective parent engagement. American Educational Research Journal, 49(4), 651-684.

Lee, C. D. (2001). Is October Brown Chinese? A cultural modeling activity system for underachieving students. American Educational Research Journal, 38(1), 97-141.

Lee, C. D. (2003). Editor's Introduction: Why we need to re-think race and ethnicity in educational research. Educational Researcher, 32(5), 3-5.

Lopez, G. (2001). The value of hard work: Lessons on parent involvement from an (im)migrant household. Harvard Educational Review, 71(3), 416-438. 
Mapp, K. L., \& Kuttner, P. J. (2013). Partners in education: A dual capacity-building framework for family-school partnerships. Austin, TX: SEDL. Retrieved from http://www. sedl. org/pubs/framework/FE-Cap-Building. pdf.

Martin, D. B. (2000). Mathematics success and failure among African-American youth: the roles of sociohistorical context, communityforces, school influence, and individual agency. Mahwah, NJ: Lawrence Erlbaum.

Martin, D. B. (2006). Mathematics learning and participation as racialized forms of experience: African American parents speak on the struggle for mathematics literacy. Mathematical Thinking and Learning, 8(3), 197-229. http://doi.org/10.1207/s15327833mt10803_2

Martin, D. B. (2007). Mathematics learning and participation in the African American context: The co-construction of identity in to intersecting realms of experience. In N. S. Nasir \& Paul Cobb (Eds.), Improving access to mathematics: diversity and equity in the classroom. New York: Teachers College Press.

Martin, D. B. (2009). Researching race in mathematics education. The Teachers College Record, 111(2), 295-338.

Mediratta, K., Shah, S., \& McAlister, S. (2009). Community organizing for stronger schools: Strategies and successes. ERIC. Retrieved from http://eric.ed.gov/?id=ED515269

Moll, L. C., Amanti, C., Neff, D., \& Gonzalez, N. (1992). Funds of knowledge for teaching: Using a qualitative approach to connect homes and classrooms. Theory into Practice, 31(2), 132-141.

Nasir, N. (2011). Racialized identities: Race and achievement among African American youth. Stanford University Press.

Nasir, N., Rosebery, A., Warren, B., \& Lee, C. D. (2006). Learning as a cultural process: Achieving equity through diversity. In R. K. Sawyer (Ed.), The Cambridge handbook of the learning sciences. Cambridge: Cambridge University Press.

Nasir, N. S., Hand, V., \& Taylor, E. V. (2008). Culture and mathematic s in school: Boundaries between "cultural" and "domain" knowledge in the mathematics classroom and beyond. Review of Research in Education, 32(1), 187-240. http://doi.org/10.3102/0091732X07308962

Nasir, N. S., \& Saxe, G. B. (2003). Ethnic and academic identities: A cultural practice perspective on emerging tensions and their management in the lives of minority students. Educational Researcher, 32(5), 14-18.

National Science Foundation, D. O. S. R. S. (2011). Women, minorities, and persons with disabilities in science and engineering: 2011. NSF, 11-309.

Oakes, J., Rogers, J., \& Lipton, M. (2006). Learning power: Organizing for education and justice. New York, NY, US: Teachers College Press. 
Olivos, E. M. (2006). The power of parents: A critical perspective of bicultural parent involvement in public schools (Vol. 290). Peter Lang.

Pea, R. \& Martin, L. (2010). Values that occasion and guide mathematics in the family. In Penuel, W.R., \& O’Connor, K. (Eds.),"Research on learning as a human science." National Society for the Study of Education Yearbook, 109(1). New York: Teachers College Press.

Peressini, D. (1996). Parents, power, and the reform of mathematics of education: An exploratory analysis of three... Urban Education, 31(1), 3.

Pollock, M. (2009). Colormute: Race talk dilemmas in an American school. Princeton University Press.

Powell, A. B. (2002). Ethnomathematics and the challenges of racism in mathematics education. In P. Valero \& O. Skovsmose (Eds.), Proceedings of the Third International MES Conference. (pp. 1-15). Copenhagen: Centre for Research in Learning Mathematics.

Pushor, D., \& Murphy, B. (2004). Parent marginalization, marginalized parents: Creating a place for parents on the school landscape. Alberta Journal of Educational Research, 50(3), $221-235$.

Remillard, J. T., \& Jackson, K. (2006). Old math, new math: Parents' experiences with standards-based reform. Mathematical Thinking and Learning, 8(3), 231-259. http://doi.org/10.1207/s15327833mt10803_3

Rogoff, B. (2003). The cultural nature of human development. Oxford [UK]; New York: Oxford University Press.

Schutz, A. (2006). Home is a prison in the global city: The tragic failure of school-based community engagement strategies. Review of Educational Research, 76(4), 691-743.

Sfard, A., \& Prusak, A. (2005). Telling identities: In search of an analytic tool for investigating learning as a culturally shaped activity. Educational Researcher, 34(4), 14-22.

Sheldon, S. B., \& Epstein, J. L. (2005). Involvement counts: Family and community partnerships and mathematics achievement. The Journal of Educational Research, 98(4), 196-207. http:/doi.org/10.3200/JOER.98.4.196-207

Sheldon, S. B., Epstein, J. L., \& Galindo, C. L. (2010). Not just numbers: Creating a partnership climate to improve math proficiency in schools. Leadership and Policy in Schools, 9(1), 27-48.

Shirley, D. (1997). Community organizing for urban school reform. University of Texas Press.

Smith, L. T. (1999). Decolonizing methodologies: Research and indigenous peoples. Zed books. 
Tucker-Raymond, E., Varelas, M., Pappas, C. C., Korzh, A., \& Wentland, A. (2007). "They probably aren't named Rachel": Young children's scientist identities as emergent multimodal narratives. Cultural Studies of Science Education, 1(3), 559-592. http://doi.org/http://dx.doi.org.offcampus.lib. washington.edu/10.1007/s11422-006-9017$\mathrm{x}$

Valencia, R. R., \& Black, M. S. (2002). 'Mexican Americans don't value education!'--On the basis of the myth, mythmaking, and debunking. Journal of Latinos \& Education, 1(2), 81.

Van Voorhis, F. L. (2003). Interactive homework in middle school: Effects on family involvement and science achievement. The Journal of Educational Research, 96(6), 323338. http://doi.org/10.1080/00220670309596616

Warren, M., Hong, S., Rubin, C., \& Uy, P. (2009). Beyond the bake sale: A community-based relational approach to parent engagement in schools. The Teachers College Record, 111(9), 2209-2254.

\section{Notes}

i Following Gutiérrez (2008) and others, we use the term nondominant to highlight the historic dynamics and power relations that have marginalized communities, such as low-income, indigenous, immigrant/refugee, and other communities of color. 